\title{
Políticas públicas, práticas de encarceramento e políticas do corpo
}

Public policies, incarceration practices and body politics

Políticas públicas, prácticas de encarcelamiento y políticas del cuerpo

Os artigos publicados neste número da Revista Polis e Psique reúnem discussões sobre políticas públicas, práticas de encarceramento e políticas do corpo. No que concerne às políticas públicas, estas têm sido não apenas campo-tema de problematização, mas de resistência, especialmente, diante das ações de desinvestimento e desmonte (Marques, Roberto, Gonçalves \& Bernardes, 2019). Os efeitos do neoliberalismo (Andrade, 2019) em nosso cotidiano são visibilizados no progressivo processo de desinvestimento das políticas públicas, incentivo à privatização e, também, na individualização/particularização da responsabilidade para com as populações no que diz respeito às condições básicas de existência, evidenciando, assim, a lógica meritocrática e contrária à suposta "dependência" do Estado, com um apelo à responsabilização dos indivíduos em seu processo de produção e cuidado da saúde e de todo bem-estar psicossocial da população (Santos, 2020).

No artigo Atuação da Psicologia no SUAS: percepções sobre Desenvolvimento Humano e Desenvolvimento Comunitário de autoria de Claudia de Godoi Ferreira de Almeida e Rafael Bianchi Silva, analisa-se a percepção de psicólogos(as) com experiência de atuação em serviços de Proteção Social Básica (PSB) do Sistema Único de Assistência Social (SUAS) acerca dos processos de desenvolvimento humano e comunitário, bem como suas possíveis articulações com o trabalho realizado nos serviços em que atuam. Os autores concluem que mesmo diante de dificuldades e limitações, prevalece nos relatos das(os) psicólogas(os) o entendimento que de os serviços PSB são espaços potenciais para o fomento a processos de desenvolvimento humano e desenvolvimento comunitário.

Em Recursos e Práticas de enfrentamento de pessoas em situação de rua: uma revisão sistemáticaCarlos Eduardo Esmeraldo Filho e Verônica Morais Ximenes analisam a produção científica acerca das estratégias de enfrentamento das pessoas em situação de rua em estudos publicados de 2008 a 2019, destacando a necessidade de investigar as pessoas em situação de rua no sentido de fortalecer estratégias de enfrentamento. 
José Bernardes da Silva Filho, Ana Carolina Peixoto do Nascimento e Gustavo Henrique Carvalho de Castrosão os autores do artigo Pacientes Trans e Cuidado Multiprofissional em Centros de Atendimento Psicossocial. Nesse texto, os autores analisam a assistência à saúde mental da população trans em dois Centros de Atenção Psicossocial (CAPS) de uma capital brasileira, a partir da realização de entrevistas com nove trabalhadores da equipe multiprofissional. Esse recurso possibilitou identificar práticas, crenças e percepções que permeiam este cuidado. Os autores concluem que a efetividade do cuidado trilha pela garantia do processo terapêutico humanizado, considerando iniquidades sociais enfrentadas (como preconiza o Sistema Único de Saúde) por pacientes trans.

O artigo Por uma Saúde e uma Psicologia equitativa e interseccional de autoria de Esmael Alves de Oliveira emerge da participação na $8^{\text {a }}$ Conferência Municipal de Saúde, ocorrida em Dourados (MS) em 2019, uma das etapas que antecederam as conferências em nível estadual (em sua $9^{\mathrm{a}}$ edição) e nacional (em sua $16^{\mathrm{a}}$ edição). Tal evento foi tomado como disparador para pensar a importância do Sistema Único de Saúde (SUS) e alguns de seus dilemas em torno da noção de equidade, as políticas de saúde em relação à saúde da população LGBTQIA+ e, por fim, os desafios impostos pelo cenário pandêmico às minorias sexuais e de gênero e as implicações disso para a práxis da Psicologia.

Francisco Valberdan Pinheiro Montenegro e Juliana Vieira Sampaio são autores do artigo Gestão Autônoma da Medicação na atenção à saúde das pessoas que usam drogas. Nesse texto, discute-se o papel da medicação na vida daqueles que a utilizam, analisando a produção acadêmica sobre a utilização da GAM no contexto da atenção à saúde das pessoas que consomem drogas.Na atenção à saúde das pessoas que consomem drogas o uso da GAM é um movimento recente a ser mapeado.Os estudos analisados elucidam especificidades, desafios e potencialidades do trabalho com a GAM no âmbito do consumo de drogas. O reduzido número de publicações sobre essa temática, entretanto, sugere serem necessários mais estudos para explorar a interface aberta pela inserção da GAM nesse contexto.

As práticas de encarceramento são discutidas tanto como estratégia de punição àqueles que cometeram crimes quanto enquanto constituição de espaços de asilamento relacionados à saúde mental. Sobre as práticas de asilamento, no artigo Nascimento e estabelecimento da assistência psiquiátrica em São Paulo: a história de um lugar para os alienados de autoria de Mara Cristina Ribeiro, Claudio José dos Santos Júnior e John Victor dos Santos Silva, discute-se a trajetória da assistência psiquiátrica no estado de São Paulo sob a perspectiva do 
primeiro local destinado à gestão médica da loucura. São abordados os aspectos gerais do início da assistência psiquiátrica brasileira; o surgimento desta assistência no estado de São Paulo; o estabelecimento do asilamento científico a partir do Hospício de Juquery como novo local para o cuidado dos alienados e o tratamento moral como terapêutica adotada; a psiquiatria higiênica do Juquery, seus desdobramentos e outras terapêuticas; e, por fim, a descentralização da assistência a partir da privatização e novas abordagens político-sociais aos pacientes hospitalizados.

No que diz respeito ao encarceramento, especialmente de idosos que é o tema do artigo aqui publicado, Oliveira, Costa e Medeiros (2013, p. 143) afirmam que "crê-se que o idoso encarcerado vivencia, no mínimo, três circunstâncias excludentes e discriminatórias em suas vidas: velhice, precárias condições sociais e, finalmente, a prisão". Além disso, Vilela, Dias e Sampaio (2021, p. 307) destacam que o crescimento do número de idosos se dá tanto fora quanto dentro dos estabelecimentos prisionais, por isso se faz importante "obter e difundir informações sobre a pessoa idosa encarcerada repousa na possibilidade de incentivar o surgimento de políticas de prevenção ao envolvimento com a criminalidade" além de produzir condições de melhoria da qualidade de vida dessa população no ambiente prisional.

Pollyanna Viana Lima, Tatiane Dias Casimiro Valença, Alessandra Souza de Oliveira e Luciana Araújo dos Reis são autoras do artigo Idosos Encarcerados: Trajetória de Vida à Luz da Teoria da Memória Coletiva no qual discutem a trajetória de vida de idosos encarcerados antes e na prisão à luz da teoria da memória coletiva/social. Estudo exploratório e descritivo, com abordagem qualitativa, triangulação de método, fundamentado na Teoria da Memória Coletiva/Social e das Representações Sociais.Foram utilizados quatro instrumentos: questionário para coleta de dados nos prontuários de saúde, de assistência social e psicologia; entrevista semiestruturada; grupo focal; e observação não participante com uso de diário de campo. Vimos que a trajetória de vida de idosos encarcerados antes e na prisão preserva a constituição família e que há uma memória preservada das vivências geradoras da prisão e da insatisfação frente ao ambiente na prisional.

As políticas do corpo reúnem, aqui, discussões sobre o corpo gordo e corpos generificados. No que concerne aos corpos gordos, o “imaginário gordofóbico é o da inaptidão física do corpo gordo, o qual usualmente é visto como um corpo sedentário, preguiçoso e incapaz de realizar atividades físicas. Ou seja, a gordofobia está impregnada na nossa concepção de corpo, projetando limitações, culpa e exclusão das pessoas gordas 
(condenadas ao exílio)” (Paim \&Kovaleski, 2020). Já no que diz respeito aos corpos generificados, Paula e Oliveira (2018, p. 87) afirmam que "“gênero" constitui-se num aparato, ou melhor, num dispositivo de produção dos significados de corpo que induz/cria uma interpretação binária e naturalizada dos sexos". Ademais, "Os corpos que desestabilizam a ordem de gênero são alvo de políticas regulatórias que buscam corrigir o que parece estar fora da norma" (Goellner, 2016, p. 34).

$\mathrm{O}$ artigo Expressões da violência associada ao corpo gordo: uma revisão bibliográfica qualitativa de autoria de Camila Aloisio Alves, Alexandre Anselmo Guilherme e Lara Vedovatto Batista dos Santos busca entender quais são as contribuições dos estudos em ciências humanas e sociais sobre violência associada à obesidade/sobrepeso, a partir de uma pesquisa bibliográfica de cunho qualitativo nas bases de dados Scielo, PubMed, Lilacs, PepSic durante os meses de dezembro de 2020 a janeiro de 2021, seguida de uma análise temática. Conclui-se que a violência associada a obesidade sofre uma forte influência dos padrões estéticos hegemonicamente aceitos, encontrando no discurso médico e de saúde pública argumentos para que pessoas obesas ou com excesso de peso sintam-se marginalizadas e culpabilizadas por suas condições

$\mathrm{O}$ artigo Produção de corpos generificados em um bloco cirúrgico: uma análise pelo trabalho como atividadede autoria de Renata da Silveira Borstmann e Fernanda Spanier Amador analisa analisamos o trabalho em saúde em um bloco cirúrgico a partir do referencial teórico da Clínica da Atividade, atentando para a especificidade da performatividade do gênero por entre esta experiência. Para tanto, produzimos um percurso transverso do ponto de vista do método, operando por entre Clínica da Atividade e pistas do Método Cartográfico, realizando, ainda, articulações com a proposta praxiográfica. As análises apontam que, apesar das fortes prescrições que compõem o trabalho em um bloco cirúrgico, os trabalhadores e trabalhadoras problematizam as normas de trabalho e de gênero nas situações laborais, produzindo estilizações.

Roberta Carvalho Romagnoli, Camila Montandon Dumont Lopes, Faedra Vilaça Ramos e Victória de Paula Roteia Oliveira são autoras do artigo A formação de futuros professores no Programa Escola Integrada (PEI). Nesse texto, tratam dos resultados parciais da pesquisa "Educação Básica e Família: reproduções e invenções no Programa Escola Integrada (PEI) de Belo Horizonte" que objetiva investigar as relações estabelecidas entre 
estudantes, professores, escolas e família. Conclui-se que a formação docente é uma experimentação na qual a invenção é necessária resistir à precarização da educação.

O artigo Casa, intimidade e cuidado: experiências no projeto Delicadas Coreografias de autoria de Beatriz Borges de Oliveira, Flávia Liberman e Luciana Vieira Caliman apresenta alguns resultados de uma pesquisa que buscou colocar em análise experiências "nas casas", desenvolvida no projeto de extensão Delicadas Coreografias, durante o ano de 2018, na Universidade Federal de São Paulo, campus Baixada Santista. As autoras tomaram como superfície de análise a experiência vivida nestes encontros, registrada em diários de campo elaborados pelas extensionistas. Conclui-se que a construção de espaços compartilhados de intimidade, afeto, formação de vínculos e a valorização dos pequenos acontecimentos/deslocamentos, podem se configurar como uma direção basilar na produção do cuidado em saúde que tem como aposta a afirmação dos processos de diferenciação.

O relato de experiência Reflexões sobre o acolhimento de profissionais de saúde na pandemia de autoria de Ana Luiza Fernandes Furtado, Déborah David Pereira, Hugo Ribeiro Lanza, Lucas Henrique de Carvalho, Mateus Fonte Boa Viana, Paula Cristina Carneiro do Prado, Mariana Pereira Santos, Camila Dulce Gorgulho Campos, Daniele Souza Steglich, Gabriela Cunha Gonçalves e Tereza Cristina Peixoto tem como objetivo compartilhar reflexões a respeito das ações de um projeto de extensão realizado em 2020 com o intuito de fortalecer trabalhadores de saúde durante a pandemia da Covid-19.Os temas convergentes nos acolhimentos foram: senso de responsabilidade, sentimento de culpa e sofrimento no trabalho; risco de contaminação, distanciamento social e estigmas; gestão do trabalho e humanização do cuidado. Por fim, considera-se a importância do projeto para o suporte e reflexão crítica das trabalhadoras sobre os processos de trabalho.

Henrique Caetano Nardi - Editor Chefe Neuza Maria de Fátima Guareschi - Editora Gerente Giovana Barbieri Galeano - Editora Assistente

\section{Referências}

Andrade, D.P. (2019). O que é o neoliberalismo? A renovação do debate nas ciências sociais. Revista Sociedade e Estado, 34(1), 211- 239. Recuperado de https://www.scielo.br/j/se/a/RyfDLystcfKXNSPTLpsCnZp/?lang=pt\&format=pdf 
Marques, C.F., Roberto, N.L.B., Gonçalves, H.S. \& Bernardes, A.G. (2019). O que significa o desmonte? Desmonte do que e para quem? Psicologia: Ciência e Profissão, 39(n.spe.2), 6-18. Recuperado de https://www.scielo.br/j/pcp/a/yvzyGKxGGDD55sqrmXBBpDF/?format=pdf\&lang=pt

Santos, R.T. (2020). O neoliberalismo como linguagem política da pandemia: a saúde coletiva e a resposta aos impactos sociais. Physis: Revista de Saúde Coletiva, 30(2), e300211. https://www.scielo.br/j/physis/a/T8WphR3ZdyFvYMVJSKfJFps/?lang=pt\&format=pdf

Oliveira, L.V., Costa, G.M.C. \& Medeiros, K.K.A.S. (2013). Envelhecimento: significado para idosos encarcerados. Rev. Bras. Geriatr. Gerontol, 16(1), 139-148. Recuperado de https://www.scielo.br/j/rbgg/a/Dp5wxHDSyTJNNtXMRh4bHvt/?lang=pt\&format=pdf

Vilela, D.S.D., Dias, C.M.S.B. \& Sampaio, M.A. (2021). Idosos encarcerados no Brasil: uma revisão sistemática da literatura. Contextos Clínicos, 14(1), 304-332. Recuperado de http://revistas.unisinos.br/index.php/contextosclinicos/article/view/21154/60748611

Paim, M.B. \&Kovaleski, D. F. (2020). Análise das diretrizes brasileiras de obesidade: patologização do corpo gordo, abordagem focada na perda de peso e gordofobia. Saúde Soc., 29(1), e190227. Recuperado de https://www.scielosp.org/pdf/sausoc/2020.v29n1/e190227/pt

Paula, F.N. de. \& Oliveira, J.H.C. de. (2018). Corpos "generificados" e centralidade do gênero masculino na educação física escolar: um estudo em representações sociais. Revista Carioca de Educação Física, 13(1), 77-93. Recuperado de https://www.revistacarioca.com.br/revistacarioca/article/view/56/66

Goellner, S.V. (2016). Jogos olímpicos: a generificação de corpos performantes. Revista USP, (108), 29-38. Recuperado de https://www.revistas.usp.br/revusp/article/view/118235 